American Journal of Pharmaceutical Education 2020; 84 (9) Article 7831.

\title{
RESEARCH
}

\section{Student Pharmacist Perspectives on Factors That Influence Wellbeing During Pharmacy School}

\author{
Jessica C. Babal, MD, ${ }^{\mathrm{a}}$ Olufunmiola Abraham, PhD, MS, BPharm, ${ }^{\mathrm{b}}$ Sarah Webber, MD, ${ }^{\mathrm{a}}$ \\ Taylor Watterson, PharmD, MS, ${ }^{\mathrm{b}}$ Pahder Moua, ${ }^{\mathrm{c}}$ Judy $\mathrm{Chen}^{\mathrm{c}}$ \\ ${ }^{a}$ University of Wisconsin-Madison, School of Medicine and Public Health, Madison, Wisconsin \\ ${ }^{\mathrm{b}}$ University of Wisconsin-Madison, School of Pharmacy, Madison, Wisconsin \\ ${ }^{\mathrm{c}}$ University of Wisconsin-Madison, Madison, Wisconsin \\ Submitted August 29, 2019; accepted February 7, 2020; published September 2020.
}

Objective. To explore first-year student pharmacist perspectives on the influence of individual, educational system, and health care system factors on their wellbeing during pharmacy school.

Methods. As part of a required course, first-year student pharmacists were required to submit reflective essays detailing the factors that most significantly contributed to their wellbeing since starting pharmacy school. Reflections from students who consented to participate during the study period from February 2019 to July 2019 were included for analysis. Qualitative thematic analysis was performed using open and axial coding, hierarchical categorization, and representative theme determination through a process of iterative review and deliberation. Coders developed a codebook with operational definitions for each emergent code. Coders met biweekly with lead researchers to ensure consistency and reliability of data analysis and to address minor discrepancies in coding. All team members discussed and revised themes until consensus regarding final representative themes was achieved.

Results. Forty-nine students (36.8\% of the first-year class) submitted reflective essays for analysis. Five themes emerged for the factors most influential on student pharmacist wellbeing: workload; learning environment culture and values; meaningful pharmacy school experiences; relationships; and personal factors. Student pharmacists did not consistently identify health care system factors as influencing their wellbeing.

Conclusion. Student pharmacists identified both education system and individual factors as influencing their wellbeing. Education systems should prioritize implementation of systematic strategies that address curricular and learning climate factors, maximize student engagement in meaningful experiences, optimize social connectedness, and provide individual student support.

Keywords: student pharmacist, pharmacy student, wellbeing, burnout, resilience

\section{INTRODUCTION}

A growing body of literature suggests that health care graduate students, including pharmacy, medical, and dental students, experience psychological distress, including anxiety, depression, or perceived stress, at significantly higher rates than their age-matched peers. ${ }^{1-3}$ Burnout, a workplace syndrome characterized by exhaustion, reduced empathy, and diminished sense of accomplishment, may develop concurrently with anxiety and depression. ${ }^{4}$ Burnout in students is associated with increased anxiety, depression, suicidal ideation, substance use, thoughts of dropping out of school, and

Corresponding Author: Jessica C. Babal, University of Wisconsin-Madison School of Medicine and Public Health, 2870 University Ave., Madison, WI 53705. Tel: 608-265-

5835. Email: babal@wisc.edu poorer school performance. ${ }^{5,6}$ In contrast, positive wellbeing is associated with improved mental health outcomes, academic self-efficacy, and better academic performance. $^{7-11}$

Studies investigating student pharmacist wellbeing have largely explored the impact of grit, resilience, selfesteem, self-awareness, and mindfulness. ${ }^{12-16}$ Although individual factors likely play a role in student pharmacist wellbeing, systems factors may be the primary drivers of wellbeing, as has been suggested for the pharmacy workplace and in other fields. ${ }^{5,17-21}$ Moreover, health care leaders, including the National Academy of Medicine (NAM), now widely recognize that both intrinsic personal and extrinsic systems factors serve as important influencers of health care student and provider wellbeing. ${ }^{22}$ The NAM encourages institutions to explore 


\section{American Journal of Pharmaceutical Education 2020; 84 (9) Article 7831.}

both individual and systems drivers of wellbeing to optimize health care student and professional wellness. ${ }^{22}$

In 2017-2018, the American Association of Colleges of Pharmacy (AACP) Student Affairs Standing Committee met to explore factors that contribute to student pharmacist wellbeing and identify strategies that promote positive wellbeing. ${ }^{23}$ In its AACP report, the Committee recognized the importance of identifying the intrinsic and extrinsic influencers of wellbeing and recommended a "multipronged approach... that includes individual and system initiatives" to promote positive wellbeing within pharmacy education. ${ }^{23}$ With limited research exploring student perspectives on the factors that contribute to wellbeing, the Student Affairs Standing Committee delivered a call-to-action to begin dialogue with student pharmacists "to learn their needs, perceptions, and recommendations to support and promote student wellbeing." 16,23,24

In this study, we sought to address this critical gap in understanding student pharmacist perspectives regarding the intrinsic and extrinsic factors that most influence student wellbeing. Specifically, we aimed to explore firstyear student pharmacist perspectives on the influence of individual, educational system, and health care system factors on their wellbeing during pharmacy school.

\section{METHODS}

We conducted a study using student reflections to understand first-year student pharmacists' perceptions of the factors that influence their wellbeing as interventions addressing early student needs may set the foundation for improving wellbeing for students as they advance through their training. All first-year student pharmacists at the University of Wisconsin-Madison School of Pharmacy, a four-year program, participated in a spring semester course focused on the social and behavioral aspects of pharmacy practice. Coursework included a small-group activity and a lecture devoted to links between leadership and professional wellbeing. To prepare for these class sessions, students were required to write a two-page essay reflecting on their wellbeing since starting pharmacy school and the individual, educational system, or health care system factors that they perceived as having the greatest impact on their wellbeing. Narrative reflections were chosen because they have been shown to provide "a rich source of data" and a "window" into the student experience that might otherwise be difficult to elicit using other approaches such as semistructured interviews and surveys, making them a useful tool for unearthing student perspectives about sensitive topics that might otherwise be difficult to share. ${ }^{25-27}$

At our institution, all first-year students complete 50 hours of community- and hospital-based patient care experiences in addition to in-class work. Students are also strongly encouraged to volunteer for additional extracurricular and clinical experiences to increase their exposure to patient care and strengthen their resumes. Most first-year students also work paid jobs within the pharmacy industry. For their reflection, students were asked to consider these experiences in pharmacy school holistically, including in-class and out-of-class experiences. To encourage organic student responses and prevent priming students on the subject of wellbeing, reflections on the subject of wellbeing were assigned to students prior to exposure to course content and graded based only whether they completed the assignment. Students were reminded that wellbeing experiences could be positive, negative, or mixed, and they were encouraged to write exclusively about experiences that contributed to their personal wellbeing, regardless of the varied examples provided in the prompt (Appendix 1).

Student reflections were submitted and analyzed during the study period, from February to July 2019. We invited all first-year students who submitted reflections to participate in the study. Students were informed that all student essays would be de-identified. Written consent was obtained for inclusion of the student reflection for analysis and for direct use of student quotations. Students completed brief demographic surveys on paper at the time of consent. The University Social and Educational Sciences Institutional Review Board deemed this study exempt.

We conducted open and axial coding using the standard content analysis approach to thematic analysis. ${ }^{28,29}$ Coding was performed using the online software, Dedoose, version 8.2.14 (www.dedoose.com). In the initial phase of analysis, two members of the research team iteratively coded all student reflections, using the constant comparative method. ${ }^{28,29}$ They developed a codebook with operational definitions for each emergent code to ensure shared understanding and consistency in coding. Next, axial coding was performed with division of codes into hierarchical groups. To further ensure consistency and reliability of data analysis, coders and lead researchers met biweekly to discuss codebook development, all coding and categorization, address minor discrepancies in coding, and revise codes until agreement was reached. In the final phase, we identified emergent themes that spanned student reflections. All team members discussed and revised themes until consensus was achieved regarding final representative themes.

\section{RESULTS}

Upon admission, the first-year pharmacy class contained 135 students with a median age of 22 years. Most first-year students identified as being female (64.5\%), an 


\section{American Journal of Pharmaceutical Education 2020; 84 (9) Article 7831.}

in-state resident (72.1\%), and either Caucasian (81.5\%) or Asian (13.3\%). A total of 133 students submitted a reflection as part of the first-year course, and $49(36.8 \%)$ consented to participate in the study (Table 1).

Five themes emerged among the factors that most influenced student pharmacists' wellbeing: workload (rigor, rapid succession examinations, cumulative workload); learning environment (culture, values); meaningful pharmacy school experiences (greater purpose); relationships (social connection, isolation); personal factors (personal traits, health, personal life circumstances). Themes and representative quotes are presented in Appendix 2.

Within the first theme, workload, students described that the required pharmacy school coursework was often overwhelming. Students identified two high-risk periods of feeling overwhelmed: initial entry into pharmacy school and periods in which several examinations and quizzes were administered in rapid succession. Students indicated that despite achieving success in their undergraduate studies, they were surprised and underprepared for the challenges and rigor of pharmacy school. Students who adapted to the workload identified a sense of accomplishment, pride, and positive wellbeing, whereas students who struggled to adapt experienced frustration and distress. Additionally, students described reduced

Table 1. Demographics of Participants in a Study to Determine Characteristics That Influence Well-being in Doctor of Pharmacy Students $(\mathrm{N}=49)$

\begin{tabular}{|c|c|}
\hline Characteristic & Students, \% \\
\hline \multicolumn{2}{|l|}{ Gender $^{\mathrm{a}}$} \\
\hline Female & 76 \\
\hline Male & 25 \\
\hline \multicolumn{2}{|c|}{ Residency status ${ }^{b}$} \\
\hline In-state & 77.6 \\
\hline Out-of-state & 22.4 \\
\hline \multicolumn{2}{|l|}{ Ethnicity $^{\mathrm{c}}$} \\
\hline Caucasian & 83.7 \\
\hline Asian & 14.3 \\
\hline Multiracial & 2.0 \\
\hline \multicolumn{2}{|l|}{ Age } \\
\hline $20-22$ & 67.3 \\
\hline $23-25$ & 18.4 \\
\hline $26-28$ & 12.2 \\
\hline $29-31$ & 2.0 \\
\hline
\end{tabular}

${ }^{a}$ No students selected non-binary, transgender male, or transgender female options for gender

${ }^{\mathrm{b}}$ No students selected international student option for residency status

${ }^{\mathrm{c}}$ No students selected Black or African American, American Indian or Alaska Native, Hispanic or Latino, Native Hawaiian or Pacific Islander options for ethnicity capacity to engage in physical health maintenance, exhaustion and illness, isolation from family and friends, and psychological distress during periods of highly concentrated coursework and knowledge assessments.

Students also described the workload impact of pharmacy employment and extracurricular activities on wellbeing. Students stated that although employment and extracurricular activities were not explicitly required, engagement in numerous extracurricular activities was implicitly expected by the institution and future employers. Taking on a multitude of extracurricular commitments was time consuming, making schedules difficult to manage and reducing time otherwise allotted for self-care and social experiences that support wellbeing.

Within the second theme, learning environment, students described how the learning environment influenced their wellbeing. Students stated that institutionally, high value was placed on student excellence, achievement, and preparation for future success. These institutional aims had mixed impact on student wellbeing. On one hand, students expressed that these institutional values provided a sense of security in believing that if they persevered through the hardships of pharmacy school, the rigor of their institution would help them become excellent pharmacists. However, students reported that emphasis on student excellence and achievement created an implicit cultural value suggesting that students should strive to be "the perfect pharmacy student who works, excels academically, holds many leadership positions, and seems to manage everything exceptionally." For some students, the perceived pressure to achieve perfection amplified their existing perfectionistic tendencies, creating distress when they did not meet the perceived performance expectations. For others, this pressure engendered feelings of inadequacy and a sense of competition that was counterproductive to their wellbeing.

Students stated that despite training in a high-pressure environment, they felt supported by an institutional devotion to mentorship, student support, community, and inclusion. There was a shared sense that the institution provided students with sufficient academic guidance and emotional support when needed, and the learning community would be readily available to meet individual student needs. Students provided multiple examples of experiences with advisors, teaching faculty members, and upperclassmen who demonstrated adherence to these values.

Within the third theme, meaningful pharmacy school experiences, students described how pharmacy school experiences that provided a personal sense of meaning or purpose had positively influenced their wellbeing. Students identified that positive patient care experiences and 


\section{American Journal of Pharmaceutical Education 2020; 84 (9) Article 7831.}

interactions with interprofessional team members helped demonstrate the greater impact of their work and helped to solidify a sense of future career fit. Additionally, students shared that curricular and extracurricular activities that they believed would help them develop into effective future pharmacists provided them with a sense of purpose in their work. Students expressed that the activities that allowed them to personally derive greater meaning or purpose could at times mitigate the negative impact of a rigorous workload.

Within the fourth theme, relationships, students identified that social connection was a salient determinant of their wellbeing in pharmacy school. Students described that trusted pharmacy school friendships provided psychological support through shared understanding of pharmacy school challenges, sense of belonging and inclusion, and joy through camaraderie. Students frequently remarked that pharmacy school friendships supported academic success. Collaborative studying augmented learning, motivated them to learn more, and encouraged healthy competition.

Students also detailed the value of relationships with family, life partners, and close friendships outside of school. These relationships provided a sense of self outside of the school setting and a helpful distraction from school life. Students pointed to the practical support they received in living with or near family in the completion of life tasks, including grocery shopping, meal preparation, and laundry. Others described that the geographical distance from family and inability to attend family events during high-stress times in pharmacy school were distressing and isolating.

Within the final theme, personal factors, students identified the impact of personal health, traits, and life circumstances on wellbeing. Overwhelmingly, students detailed ways in which they were resilient and adaptable, persevering through challenging pharmacy school experiences. Students identified themselves as hard workers who held themselves to exceedingly high standards, which often led to academic accomplishment. However, students shared that although their perfectionism could drive academic success, it frequently led to distress when they fell short of performance expectations or compared themselves to peers. Additionally, students indicated that they struggled with setting personal boundaries, including limiting the time they spent studying and participating in extracurricular activities. As a result, students described spending less time on personal health and non-school life experiences.

Additionally, students identified how personal health and life circumstances contributed to wellbeing. Good health was supportive of wellbeing, while personal health challenges, including mental (anxiety, depression), emotional (isolation, feelings of inadequacy), physical health (illness, fatigue), and personal stressors (long commutes, financial challenges) had the potential to interfere with school performance and increased psychological distress.

\section{DISCUSSION}

Despite growing recognition by the AACP and educators that student pharmacist wellbeing initiatives should be prioritized, knowledge regarding student perceptions of factors that influence wellbeing remains limited. ${ }^{16,23,30,31}$ Students in this study indicated that rigorous coursework, rapid succession examinations, and cumulative curricular and extra-curricular workload were salient contributors to distress in pharmacy school. Students identified that finding meaning or purpose in their work helped to mitigate some of the negative impact of the rigorous workload. Institutional emphasis on student success helped some students feel secure, supporting the student belief that a rigorous academic environment would support professional growth, while other students felt distressed by the high-pressure environment. Institutional focus on mentorship and community and social connection were supportive of student wellbeing. Students identified mental health, personal traits, and life circumstances as important influencers of wellbeing. Notably, despite participation in required and extracurricular clinical experiences, students in our study did not delineate health care system factors as influencers of their wellbeing.

The influence of workload on student pharmacist wellbeing is supported by the literature on student pharmacists, pharmacists, and work-stress. ${ }^{17-21,30,32-36}$ Thematic analysis of the experiences of student pharmacists' in Ireland identified that course workload and multiple simultaneous deadlines often left students feeling overwhelmed and with limited time to spend in activities that reduced stress. ${ }^{16}$ Likewise, classwork, out-of-class work, and timing of examinations have been ranked among the most prominent stressors for student pharmacists. ${ }^{24}$ Efforts to mitigate the stress of traditional coursework and concentrated examination schedules have been trialed within health care professional student education with promising results. ${ }^{37-39}$ Curricular models that reduce time spent in class, utilize prerecorded lectures and online coursework, and promote active in-class learning, have been shown to improve student pharmacists' satisfaction and examination scores. ${ }^{37,38}$ Additionally, in a study involving medical students, systematic scheduling and curricular changes, including adjusting examination schedules to allow adequate time between learning assessments, reducing in-class time requirements, adapting 


\section{American Journal of Pharmaceutical Education 2020; 84 (9) Article 7831.}

pass-fail grading, and developing learning communities resulted in significantly lower psychological distress and improved class cohesion, with no detriment to standardized testing scores. ${ }^{39}$ These findings suggest that education system interventions, particularly those that address curriculum delivery and approach to assessments, may potentially be used to reduce distress related to course workload and rigor without sacrificing student learning outcomes.

Prior studies of pharmacy and medical students have also identified the impact of learning climate on student experiences, as was described in our study. ${ }^{31,40-42}$ In pharmacy schools with multiple campuses, differences in student-perceived stress and self-efficacy were found across institutions. ${ }^{31}$ Learning climate factors, including large class size and less faculty support, were suggested as possible contributors. ${ }^{31}$ Similarly, medical students have been shown to experience lower rates of burnout when they perceive that their educational institution (advisors, leadership, faculty members, peers) support them, faculty members prioritize student education, and the school promotes collaborative learning. ${ }^{40}$ Numerous studies demonstrate that collaborative learning and working environments and positive social connection are associated with greater engagement, professional accomplishment, and less burnout. ${ }^{4,5,40,43,44}$ The students in this study similarly identified that trusted pharmacy student relationships and collaborative learning environments with peers, upperclassmen, and supportive faculty members were important influencers of wellbeing, providing emotional support and augmenting motivation to learn. Creating peer mentoring programs, student learning communities, and team-based learning opportunities may all serve as feasible means of encouraging positive social connection among peers, augmenting student learning, and improving student wellbeing, as these interventions have previously been shown to be beneficial in the health care professional student setting. ${ }^{39,45}$

Our findings indicated that both mandatory and voluntary clinical and academic experiences had positive impact on student wellbeing when the activities were perceived as personally meaningful. Although the impact of meaningful experiences on health care student wellbeing has not been well studied, the literature increasingly suggests that engagement in meaningful work reduces health care professional burnout. ${ }^{32,46}$ Shanafelt and colleagues surveyed physicians about the work activities that were most personally meaningful, including time spent in patient care, research, education, administration, and nonpatient care tasks, and percentage of time spent in each activity. Physicians spending more than $20 \%$ of their time in work they deemed most personally meaningful had significantly lower burnout compared to physicians spending less time in meaningful work. ${ }^{32}$ Similarly, engagement in work perceived by occupational therapists as personally valuable or meaningful has been correlated with lower burnout and stronger sense of professional identity. ${ }^{46}$

These findings, along with the findings in our study, suggest that maximizing student engagement in personally meaningful experiences would be beneficial for student wellbeing. This may be achieved in part by requiring students to participate in interprofessional and healthcarerelated experiences early in their matriculation, as clinical experiences were described by students in our study as supportive of student professional growth and a sense of career fit. Additionally, students should be encouraged to choose their voluntary extracurricular commitments with intentionality, taking on only activities that support the student's vision of meaningful student pharmacist work. Likewise, students should be discouraged from adding extracurricular activities solely as a means of bolstering their resume, as this increases workload demands and may increase students' perceived stress.

Finally, the influence of individual factors, including mental health, personal traits, and life circumstances, on student wellbeing has been well studied. ${ }^{12-16,24,47}$ Unique to our study is that students described themselves fairly universally as resilient and provided concrete examples of ways they strived to adapt to pharmacy school. Students described that despite their resilient traits, acute and chronic stressors from pharmacy school could accumulate and result in sustained negative wellbeing that was difficult to overcome. Therefore, while students would likely benefit from readily available mental and physical health resources, systemic education and institutional changes that support individual student wellbeing remain imperative.

There are several limitations of this study. First, this research was conducted at a single Midwest institution in the United States and had a small sample size, which may limit the generalizability of our findings. Second, data were collected from only first-year students, which sheds light on the early student pharmacist experience but may not reflect the experience of more advanced student pharmacists. Third, because of the potentially sensitive nature of the content students provided in their essays, our sample was limited to students who consented to submitting their reflections for analysis, potentially leading to selection bias and limiting the representativeness of our findings. However, consistency of themes discussing factors affecting wellbeing suggests that the study population represented a variety of students with a range of wellbeing experiences, both positive and negative. Finally, because 


\section{American Journal of Pharmaceutical Education 2020; 84 (9) Article 7831.}

the prompt listed an array of factors that could potentially contribute to wellbeing, students might have described factors in their reflections that they might not have otherwise considered had examples not been provided.

Future studies could aim to understand the influencers of wellbeing at institutions across the United States and internationally, and explore the perspectives of student pharmacists in later years of the curriculum to understand how influencers of student wellbeing shift over time. Future studies could also seek to quantify the degree to which each factor influences wellbeing, so that educational systems could appropriately target interventions that simultaneously support educational success and promote positive wellbeing. Additionally, because meaningful work and its importance in pharmacy education remains underexplored, future studies should investigate the concept of meaningful work, especially as it relates to student wellbeing. Obtaining ongoing input directly from student pharmacists regarding their wellbeing will remain imperative in addressing the current gaps in our understanding of student wellness needs and should guide future curricular and institutional changes that cultivate positive student wellbeing.

\section{CONCLUSION}

This study aimed to explore first-year student pharmacists' perspectives on the influence of individual, educational system, and health care system factors on their wellbeing during pharmacy school. Results indicated that workload, learning climate, meaningful experiences, social connection, personal traits, and life circumstances were salient influencers on wellbeing. Education systems should prioritize systematic strategies that address curricular and learning climate factors, maximize student engagement in meaningful experiences, optimize social connectedness, and provide individual student support.

\section{ACKNOWLEDGMENTS}

The authors acknowledge Christine Richards for her assistance with formatting and manuscript submission.

\section{REFERENCES}

1. Geslani GP, Gaebelein CJ. Perceived stress, stressors, and mental distress among doctor of pharmacy students. Soc Behav Personal. 2013;41(9):1457-1468.

2. Brazeau CM, Shanafelt T, Durning SJ, et al. Distress among matriculating medical students relative to the general population. Acad Med. 2014;89(11):1520-1525.

3. Stormon N, Ford PJ, Kisely S, Bartle E, Eley DS. Depression, anxiety and stress in a cohort of Australian dentistry students. Eur $J$ Dent Educ. 2019;23(4):507-514.

4. Maslach C, Jackson SE. The measurement of experienced burnout. J Organ Behav. 1981;2(2):99-113.
5. Dyrbye L, Shanafelt T. A narrative review on burnout experienced by medical students and residents. Med Educ. 2016;50(1):132-149. 6. Dyrbye LN, Thomas MR, Power DV, et al. Burnout and serious thoughts of dropping out of medical school: a multi-institutional study. Acad Med. 2010;85(1):94-102.

7. Schaufeli WB, Bakker AB. Job demands, job resources, and their relationship with burnout and engagement: a multi-sample study. $J$ Organ Behav. 2004;25(3):293-315.

8. Schaufeli WB. Engaging leadership in the job demands-resources model. Career Development International. 2015;20(5):446-463.

9. Trockel M, Bohman B, Lesure E, et al. A brief instrument to assess both burnout and professional fulfillment in physicians: Reliability and validity, including correlation with self-reported medical errors, in a sample of resident and practicing physicians. Acad Psychiatr. 2018;42(1):11-24.

10. Thomas MR, Dyrbye LN, Huntington JL, et al. How do distress and well-being relate to medical student empathy? A multicenter study. J Gen Intern Med. 2007;22(2):177-183.

11. Burr J, Beck Dallaghan GL. The relationship of emotions and burnout to medical students' academic performance. Teach Learn Med. 2019;31(5):479-486.

12. Stoffel JM, Cain J. Review of grit and resilience literature within health professions education. Am J Pharm Educ. 2018;82(2).

13. McAllister M, McKinnon J. The importance of teaching and learning resilience in the health disciplines: a critical review of the literature. Nurse Educ Today. 2009;29(4):371-379.

14. Sa B, Ojeh N, Majumder MAA, et al. The relationship between self-esteem, emotional intelligence, and empathy among students from six health professional programs. Teach Learn Med. 2019;1-8. 15. Cooley JH, Larson S. Promoting a growth mindset in pharmacy educators and students. Curr Pharm Teach Learn. 2018;10(6): 675-679.

16. O'Driscoll M, Byrne S, Kelly M, Lambert S, Sahm LJ. A thematic analysis of pharmacy students' experiences of the undergraduate pharmacy degree in Ireland and the role of mindfulness. Am J Pharm Educ. 2019;83(1):6457.

17. Chui MA, Look KA, Mott DA. The association of subjective workload dimensions on quality of care and pharmacist quality of work life. Res Social Adm Pharm. 2014;10(2):328-340.

18. Jones GM, Roe NA, Louden L, Tubbs CR. Factors associated with burnout among US hospital clinical pharmacy practitioners: results of a nationwide pilot survey. Hosp Pharm. 2017;52(11):742-751.

19. Barnett CW, Hopkins WA, Jr., Jackson RA. Burnout experienced by recent pharmacy graduates of Mercer University. Am J Hosp Pharm. 1986;43(11):2780-2784.

20. Lindfelt T, Ip EJ, Gomez A, Barnett MJ. The impact of work-life balance on intention to stay in academia: results from a national survey of pharmacy faculty. Res Social Adm Pharm.

2018;14(4):387-390.

21. El-Ibiary SY, Yam L, Lee KC. Assessment of burnout and associated risk factors among pharmacy practice faculty in the United States. Am J Pharm Educ. 2017;81(4):81475.

22. Brigham T, Barden C, Legreid Dopp A, et al. A journey to construct an all-encompassing conceptual model of factors affecting clinician well-being and resilience. NAM Perspectives. 2018.

23. Miller ML, Boyer C, Emerson MR, et al. Report of the 20172018 Student Affairs Standing Committee. Am J Pharm Educ. 2018; 82(7):7159.

24. Marshall LL, Allison A, Nykamp D, Lanke S. Perceived stress and quality of life among doctor of pharmacy students. Am J Pharm Educ. 2008;72(6). 


\section{American Journal of Pharmaceutical Education 2020; 84 (9) Article 7831.}

25. Karnieli-Miller O, Vu TR, Holtman MC, Clyman SG, Inui TS. Medical students' professionalism narratives: a window on the informal and hidden curriculum. Acad Med. 2010;85(1):

124-133.

26. Fischer MA, Harrell HE, Haley HL, et al. Between two worlds: a multi-institutional qualitative analysis of students' reflections on joining the medical profession. $J$ Gen Intern Med 2008;23(7):958-963.

27. Gaufberg EH, Batalden M, Sands R, Bell SK. The hidden curriculum: what can we learn from third-year medical student narrative reflections? Acad Med. 2010;85(11):1709-1716.

28. Bradley EH, Curry LA, Devers KJ. Qualitative data analysis for health services research: developing taxonomy, themes, and theory. Health Serv Res. 2007;42(4):1758-1772.

29. Basics of Qualitative Research Techniques and Procedures for Developing Grounded Theory. 4th ed. Thousand Oaks, CA:Sage; 2014.

30. Basson MJ, Rothmann S. Antecedents of basic psychological need satisfaction of pharmacy students: the role of peers, family, lecturers and workload. Res Social Adm Pharm. 2018;14(4):

372-381.

31. Awe C, Gaither CA, Crawford SY, Tieman J. A Comparative analysis of perceptions of pharmacy students' stress and stressors across two multicampus universities. Am J Pharm Educ. 2016; 80(5):82.

32. Shanafelt TD, West CP, Sloan JA, et al. Career fit and burnout among academic faculty. Arch Intern Med. 2009;169(10):990-995.

33. de Beer LT, Pienaar J, Rothmann S, Jr. Work overload, burnout, and psychological ill-health symptoms: a three-wave mediation model of the employee health impairment process. Anxiety Stress Coping. 2016;29(4):387-399.

34. Jourdain G, Chenevert D. Job demands-resources, burnout and intention to leave the nursing profession: a questionnaire survey. Int $J$ Nurs Stud. 2010;47(6):709-722.

35. Van den Broeck A, Vansteenkiste M, De Witte H, Lens W. Explaining the relationships between job characteristics, burnout, and engagement: the role of basic psychological need satisfaction. Work \& Stress. 2008;22(3):277-294.
36. Demerouti E, Bakker AB, Nachreiner F, Schaufeli WB. The job demands-resources model of burnout. J Appl Psychol.

2001;86(3):499-512.

37. Wong TH, Ip EJ, Lopes I, Rajagopalan V. Pharmacy students' performance and perceptions in a flipped teaching pilot on cardiac arrhythmias. Am J Pharm Educ. 2014;78(10).

38. Giuliano CA, Moser LR. Evaluation of a flipped drug literature evaluation course. Am J Pharm Educ. 2016;80(4):66.

39. Slavin SJ, Schindler DL, Chibnall JT. Medical student mental health 3.0: Improving student wellness through curricular changes. Acad Med. 2014;89(4):573-577.

40. Dyrbye LN, Thomas MR, Harper W, et al. The learning environment and medical student burnout: a multicentre study. Med Educ. 2009;43(3):274-282.

41. Monrouxe LV, Rees CE, Dennis I, Wells SE. Professionalism dilemmas, moral distress and the health care student: Insights from two online UK-wide questionnaire studies. BMJ Open. 2015;5(5): e007518.

42. Bradley F, Steven A, Ashcroft DM. The role of hidden curriculum in teaching pharmacy students about patient safety. Am J Pharm Educ. 2011;75(7):143

43. Shanafelt TD, Noseworthy JH. Executive leadership and physician well-being: nine organizational strategies to promote engagement and reduce burnout. Mayo Clin Proc. 2017;92(1):129-146.

44. Truchot D, Deregard M. Perceived inequity, communal orientation and burnout: the role of helping models. Work \& Stress. 2010;15(4):347-356.

45. Raub JN, Fiorvento A, Franckowiak TM, Wood T, Gortney JS. Implementing and sustaining a mentorship program at a college of pharmacy: the keys to successful mentorship. Curr Pharm Teach Learn. 2017;9(2):296-301.

46. Scanlan JN, Hazelton T. Relationships between job satisfaction, burnout, professional identity and meaningfulness of work activities for occupational therapists working in mental health. Aust Occup Ther J. 2019.

47. Dyrbye LN, Thomas MR, Huntington JL, et al. Personal life events and medical student burnout: a multicenter study. Acad Med. 2006;81(4):374-384. 


\section{American Journal of Pharmaceutical Education 2020; 84 (9) Article 7831.}

\section{Appendix 1. Prompt for Student Pharmacist Wellbeing Reflection}

Assignment Background: Individual factors, educational/institutional factors, and healthcare system factors all may have an impact on pharmacy student wellbeing. The influence that these factors have on each individual's wellbeing can be positive, negative, or mixed.

Examples of these factors may include, but are not limited to:

Individual factors:

Personal characteristics: Personality, assertiveness, ability to cope with challenge and bounce back, ability to set boundaries between work and personal life

Personal health: Physical, mental health

Responsibilities outside of academic work: Home/caregiving responsibilities

Engagement outside of academic work: Hobbies, communities, including special interest groups, religious groups or practice, family/friend networks

Educational/institutional system factors:

Perceived institutional values: Culture of the institution, including spoken and unspoken rules of engagement and/or values

Nature of pharmacy education: Workload, student evaluation, degree to which curriculum prepares students

Faculty behaviors: Professional/unprofessional treatment of students, colleagues, and patients; mentorship

Sense of community: Collegiality, competition, hierarchy

Resources: Educational support, mental health and wellbeing support availability

Health systems factors:

Equity: Patient equity/inequities in healthcare and insurance

Patient safety: Effectiveness of systems approach to medical/medication errors, safety issues, and poor patient outcomes

Patient care, task efficiency: Efficiencies/inefficiencies in electronic health record, requirements to complete competing tasks/ demands on the job

Interdisciplinary care: Effectiveness of local approach to interdisciplinary care

Assignment: In your experiences in pharmacy school, what individual, education system, or healthcare system factor(s) have had the greatest impact (positively, negatively, or mixed) on your wellbeing? 


\title{
American Journal of Pharmaceutical Education 2020; 84 (9) Article 7831.
}

\author{
Appendix 2. Themes and Supporting Verbatim Quotes for the Intrinsic and Extrinsic Factors that Most Influence Student \\ Pharmacist Wellbeing
}

\begin{tabular}{ll}
\hline Theme & Verbatim Quotes \\
\hline 1. Workload & I went from studying one, maybe two, days a week in my prerequisite work, to having to study seven days
\end{tabular}
a week, thinking of pharmacy nearly all day. I was overtired, and in a constant state of stress.

My first semester of pharmacy school was challenging because for eight weeks straight, I had to take at least one exam and one quiz every single week, in addition to completing quizzes, lab reports, and assignments for my six classes.

When push comes to shove, and I have already taken at least one exam and one quiz every single week in the month prior to my physiology exam, cramming is a survival strategy, even if it means sacrificing my personal health.

As the semester continued, the course load greatly impacted my well-being. I was drinking more energy drinks and consistently eating snacks while studying. I stopped caring about my daily exercise and spent it staring at my computer screen to finish assignments. My sleeping pattern was also affected. It was quite irregular and sometimes I felt very tired.

Sitting in [the] library staring down hour 70 of studying in the past 6 days, I started to really feel the idea of burnout. I could feel that my motivation was at an all-time low. The pillars of burnout were all there, the depersonalization, the diminished feeling of accomplishment. I really didn't want to talk to anyone or do anything, especially more studying.

After going to school all day and then to work in a pharmacy, I don't have much energy left for hobbies, even if I did have the time.

The stress of expectations of participating in extra-curricular and co-curricular activities has contributed to the feeling that I don't have time for some basic functions, such as keeping my apartment clean or doing dishes regularly.

2. Learning Upon first starting school here I was intimidated by and resentful of the purposefully difficult exams, fast

Environment paced classes, and overall high expectations of us... I am now more thankful for and happy that the school pushes us... It means that we'll be better pharmacists in the future which I find very comforting.

The perceived institutional values, like the expectations for everyone to hold several leadership roles and other expectations surrounding professional development, are overwhelming and stressful. . .Students are constantly asked about what they have done to gain leadership roles, what they plan to do if they can even land a leadership role, and how they are going to do MORE. There is always a perceived expectation to do more and more and more. This piece of pharmacy school has negatively impacted my wellbeing and I know it has had an impact on students around me as well because it constantly reminds us that we are never doing enough.

I am anxious that I will not be able to accomplish enough to be a competitive pharmacist upon graduation. The pressure that I have experienced so far to take on more tasks is exacerbated by the school faculty and administration's warnings about the state of our profession. It is this pressure, an education/institutional factor, that I consider having the most substantial impact on my wellbeing as a pharmacy student.

[This] is a prestigious school, and I am reminded of it often. In order to be successful later, I must compete for leadership positions with a room full of people who all have the same goals as me.

I feel a strong sense of community within the school of pharmacy. Developing new friendships with people who are navigating a lot of the same experiences as well as getting to know upperclassmen through involvement in several student organizations has had a positive impact on my wellbeing. Additionally, I have felt supported by everyone that I've had the chance to interact with including students in my DPH 1 class, upperclassmen, preceptors, as well as the faculty and staff.

The faculty has had a positive impact on my well-being and I usually feel like the faculty has a genuine care for the students and their outcome in classes.

The atmosphere of the school also comforted me, as I felt at home. Everyone says hi to everyone, and I feel like I belong to a family of pharmacists. 
American Journal of Pharmaceutical Education 2020; 84 (9) Article 7831.

(Continued)

\begin{tabular}{ll}
\hline Theme & Verbatim Quotes \\
\hline 3. Meaningful & I've volunteered at a couple [student-run free clinic] shifts and working with the other students helps me gain
\end{tabular}

Pharmacy

School

Experiences

4. Relationships
I've volunteered at a couple [student-run free clinic] shifts and working with the other students helps me gain a sense of pride in what I can teach them while also appreciation towards what they contribute to the team and can show me. They give me reassurance I will be successful in the future.

[At the student-run free clinic] another student and I were able to spend a long time with a patient who came in with a variety of health concerns including a wart on her hand, depression, weight loss, and barriers to receiving appropriate care outside of free clinics. We were able to address all of her health concerns as well as link her up to a primary care provider through a referral. This experience was so impactful to me because it showed the power of working in a team. I also realize how important it is to me to work with patients.

First semester I became very involved in [the student-run free clinic] which is an organization that spans across multiple health sciences. Through meeting students in many programs and sharing and learning about each other's mutual passion of giving free health care to the underserved population of [this city], I have been inspired more to do course work well.

Classes in pharmacy school help me understand the importance of pharmacists in the health care system, which assures me that I chose the correct field of work.

The materials I learned in my classes were good resources to refer to while on my [inter-professional education] clerkships. I felt confident and comfortable asking the pharmacist questions and was prepared.

Working at [the] Hospital makes my schedule very busy, but I also appreciate the experience it has given me.

The stressful nature of pharmacy school has forged a deep bond between me and my friends. It is the type of bond that can only be formed when another knows exactly what you are going through. Together we work to transform the competition into a manner in which we push each other to do better than we did before. We turn the expectations into a goal in which we help each other reach. We turn the stress into a situation that will bond us for life.

I have been able to connect with really great new friends who support each other instead of compare each other. An example would be last semester when for several exams, I would study with a few classmates who would support each other while we studied for exams. I felt included and energized by these students.

I soon found a great group of friends that I could be myself with, and we helped each other get through the semester. We help each other study, we congratulate each other when we accomplish our goals, and we do a lot of things together outside of school to de-stress.

My family has been so supportive of me throughout school. I live with my husband and dog. . . It's a relief to be able to come home to them every night and be able to talk about my day at school or pretend I'm not a pharmacy student for just a second.

Having the support needed at home has been essential to my success so far. My husband and my sister, who also lives with us, have been an immense help to me. When I need to buckle down and focus on studying, they are there to do whatever else needs to be done from doing the shopping, cooking, cleaning, etc. I cannot say enough about how important that has been for me. We are a good team, which helps tremendously.

Living in a family has given me emotional support, as well as physical support around the house; my in-laws helped me in doing my chores like cooking and buying groceries.

I had classes all morning, spent the afternoon in the library studying, then... I was pondering the fact that I hadn't been able to go home since school started because it takes me more than five hours to drive there. I think the realization that I wouldn't get to see my family for another month made it all come crashing down, and I cried right there. 
American Journal of Pharmaceutical Education 2020; 84 (9) Article 7831.

(Continued)

Theme
$\begin{aligned} & \text { I. Personal } \\ & \text { Factors }\end{aligned}$
schould consider myself to be resilient and capable of facing challenges and persevering. Starting pharmacy
[student] representative after just one month of being in school. I did not get the position. At first, I was
disappointed in myself but then I became proud that I had given it a chance. I gave a speech in front of
200+ people that I barely knew... Although I didn't win, I was proud that I tried.
I may be under more stress than I was in the past, but I am learning to better cope with it and better manage
my time... I still must improve, but I am slowly making progress towards more effective study habits and
a healthier lifestyle.
I had a few setbacks but eventually I learned how to better effectively study. I also learned how to better
manage my time and I even decided to get involved in some student organizations.
In terms of personal characteristics, I would consider myself a perfectionist which has both positive and
negative influences on my wellbeing. In the positive sense, this factor helps me complete tasks that require
a lot of attention to detail well and I always put my best effort into something. But in the negative sense, I
can get angry at myself if I fail at something because I question what I did wrong and what happened to my
process.
Being type A and then entering a demanding environment, such as pharmacy school, is sure to breed stress
and anxiety. This has had negative impacts on my well-being as sleep, work-life balance, and my 'me
time' have been sacrificed at times so that I may meet the expectations set forth by the pharmacy
profession.
I began to struggle to complete my work due to extreme fatigue and stress from traveling every day. The
exhaustion also prevented me from paying attention in class and connecting more with my peers, and this
proliferated the mental strain I was experiencing.

